\title{
Study of the Performance Reduction Due to the Dirt Effect in the Photovoltaic Systems of UTFPR - Curitiba
}

\author{
Édwin Augusto Tonolo ${ }^{1 *}$, Juliana D'Angela Mariano ${ }^{2}$, Carlos Eduardo Teixeira Neves ${ }^{3}$, \\ Alynne Penha de Mendonça Silva ${ }^{3}$, Jair Urbanetz Junior ${ }^{1,2}$ \\ ${ }^{1}$ Programa de Pós-Graduação em Sistemas de Energia, Universidade Tecnológica Federal do Paraná, Curitiba, \\ Brasil; ${ }^{2}$ Programa de Pós-Graduação em Engenharia Civil, Universidade Tecnológica Federal do Paraná, Curitiba, \\ Brasil; ${ }^{3}$ Departamento Acadêmico de Eletrotécnica, Universidade Tecnológica Federal do Paraná, Curitiba, Brasil.
}

\begin{abstract}
Photovoltaic systems have been consolidated in the global energy scenario as an option of low environmental impact energy generation, high reliability and great applicability in urban centers, acting like energy generators near the point of consumption. The Federal University of Technology of Paraná (UTFPR), with the proposal of testing the performance of grid-connected photovoltaic systems (On Grid PV Systems) and help its entry into the Brazilian energy matrix, implemented this technology in two of its buildings: Green Office (GO) And Neoville. This paper analyzed the effects of dust on the Photovoltaic Systems performance based on daily energy. The analysis was carried out from the solar irradiance data from the places where the panels are installed and the electrical power data collected at the mass memory of the inverter of the two systems, in order to be analyzed and compared before and after the cleaning of the photovoltaic modules. The results at the end of the study indicate that dust directly impacts in the performance of the PV system.
\end{abstract}

Key-words: photovoltaic system, dust, power generation.

*Author of correspondence: edwintonolo@gmail.com 


\section{INTRODUCTION}

The increase in the use of electricity generation technologies through renewable sources has been highlighted in recent years by the significant contribution to the global energy matrix $^{1}$. In this scenario, the generation through photovoltaic systems stands out because it is a source of low environmental impact, high reliability and great applicability in urban centers.

Brazil has a great potential of photovoltaic generation. However, this energy source has an installed capacity of about $0.09 \%$ in the electric matrix, and up to August 2017 the installed capacity of photovoltaic systems in the country was $282.4 \mathrm{MWp}(176.2 \mathrm{MWp}$ outside the energy compensation system and 106.2MWp in micro and mini generation registered in the compensation system $)^{2},{ }^{3}$. With the purpose of analyzing this technology and encouraging its entry into the country, Grid Tie Photovoltaic Systems were installed in the Green Office (GO), with $2.1 \mathrm{kWp}$, and Neoville, with $10.2 \mathrm{kWp}$, of The Federal University of Technology of Paraná (UTFPR) for the generation of electric energy as micro generation (less than 75kWp). The GO's system has been in operation since December 2011 and the Neoville's system has been in operation since February 2016, contributing both to the generation of energy to the facilities and also to assist in research on the subject of Photovoltaic Energy ${ }^{4}$.

The loss factors of a PV Systems may be related to several factors, among them are temperature and dirt. The understanding of the power loss factors of an installation is fundamental for optimizing the energy production. This article will deal with the losses related to dirt as it is an important aspect for the performance. However, the accumulation of dirt and particles in the modules causes considerable decreases in energy production.

The dirt losses analysis will be based on the monthly energy production of the photovoltaic plants under study, and factors such as the technology of photovoltaic modules, geographical location, local climate, among others will be considered. After that, a comparison of the system's production before and after cleaning the panels is carried out.

\section{MATERIAL AND METHODS}

In 2015, UTFPR acquired a thermoelectric piranometer model CMP 03, from Kipp \& Zonen manufacturer and a Datalogger CR1000 from Campbell Scientific manufacturer, which was installed in the cover of Block B, at the central campus, downtown in Curitiba $^{5}$. The thermoelectric pyranometer is designed to perform measurements of the global irradiance, usually in the horizontal plane and consists of a thermopile sensor with a spectral response up to $2500 \mathrm{~nm}^{6}$.

In industrial areas, with high traffic of cars, or with a dry climate, for example, there is a greater accumulation of dirt in the photovoltaic modules. The effect of the accumulation of dirt is reduced when it is cleaned with rainwater. A minimum angle of 10 degress is recommended, but the more inclined the installation, the better is the self-cleaning. The design of the panel can help to promote a greater accumulation of dirt when it contains raised edges ${ }^{7}$.

Data collection of solar irradiation was released by the National Institute of Meteorology $\left(\right.$ INMET) ${ }^{8}$ and the pyranometer installed at UTFPR were used to select days with similar characteristics. A comparison was made between the INMET data, available per hour, and the UTFPR pyranometer, per minute, and after that, similar results were observed. 


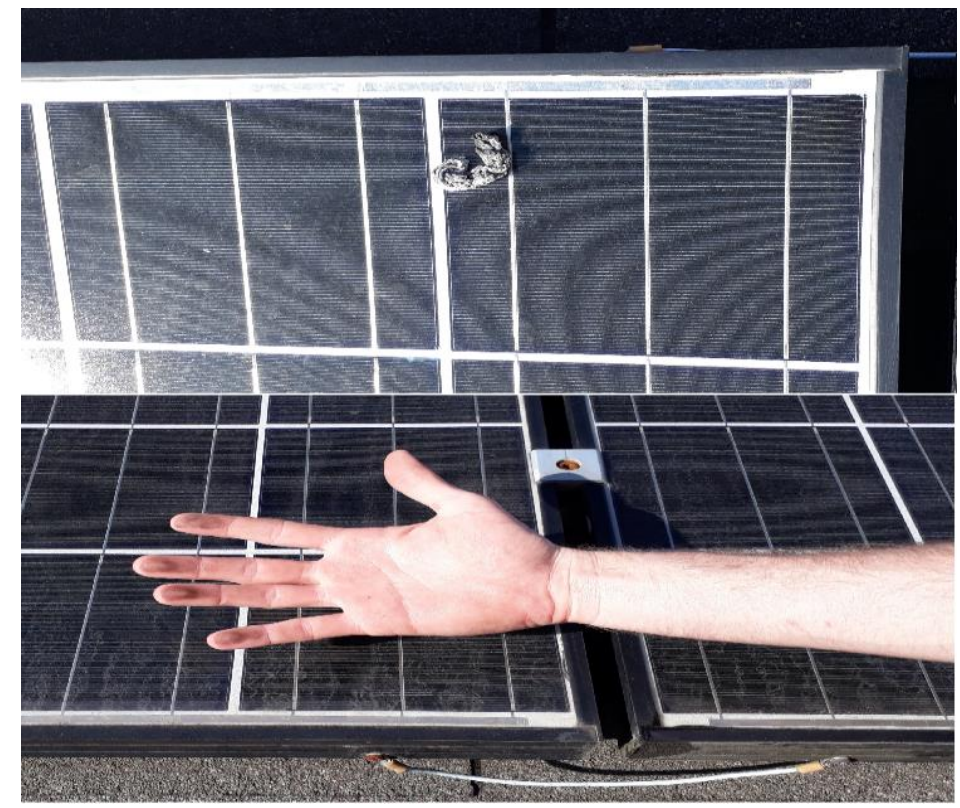

Figure 1 - Condition of GO modules before cleaning

The cleaning of the photovoltaic panel in the GO was performed on 06/26/17 in the morning and this process lasted approximately one hour and thirty minutes. Figure 1 and Figure 2 illustrate the conditions before and after cleaning. The cleaning of the photovoltaic panel of Neoville, was performed on 06/28/17 in the morning and lasted approximately two hours. In Figure 3 this process is illustrated. For the cleaning of the modules in both facilities powder soap, broom and water were used. It was verified that the GO presented the largest amount of dirt, characterized by dark color due to the soot released by the vehicles. Neoville's headquarters is located in a region farther from the center, and the dirt in the modules was mostly composed by dust. In addition, bird wastes were also found, see Figure 1, mainly at Neoville headquarters. Since the panels are located in high places, the cleaning activity depended mainly on weather conditions, because it would be dangerous to perform them on rainy days.

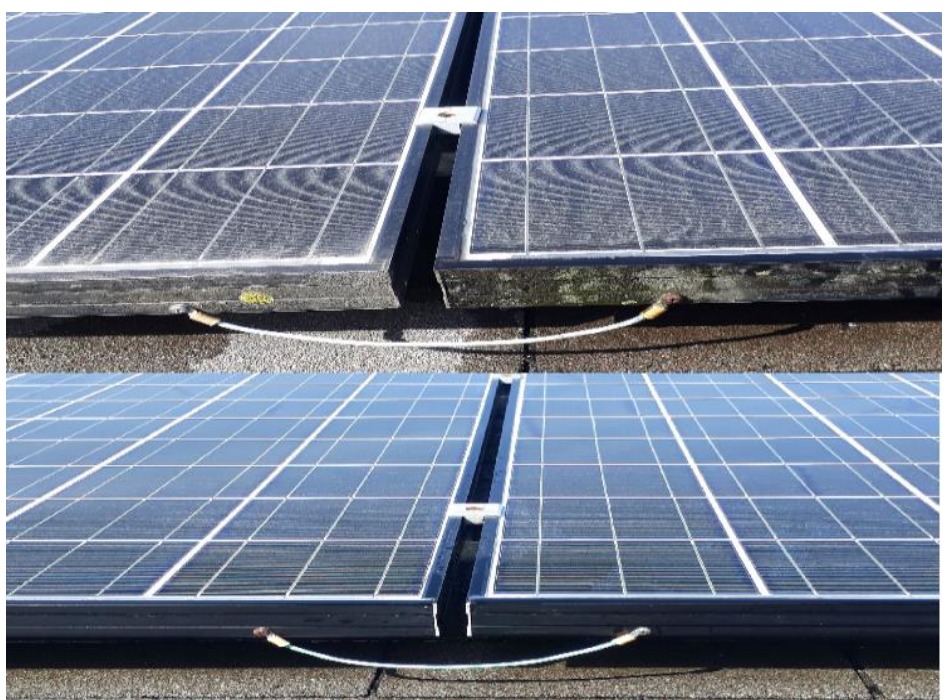

Figure 2 - Comparison before and after cleaning

Daily irradiance per hour graphs for the months of May and June were devised with the intention of selecting two days with similar characteristics, one in the period prior to the 
cleaning and another after that. The objective was to carry out the comparison with indexes of maximum irradiance, so that the difference in system performance could be analyzed.

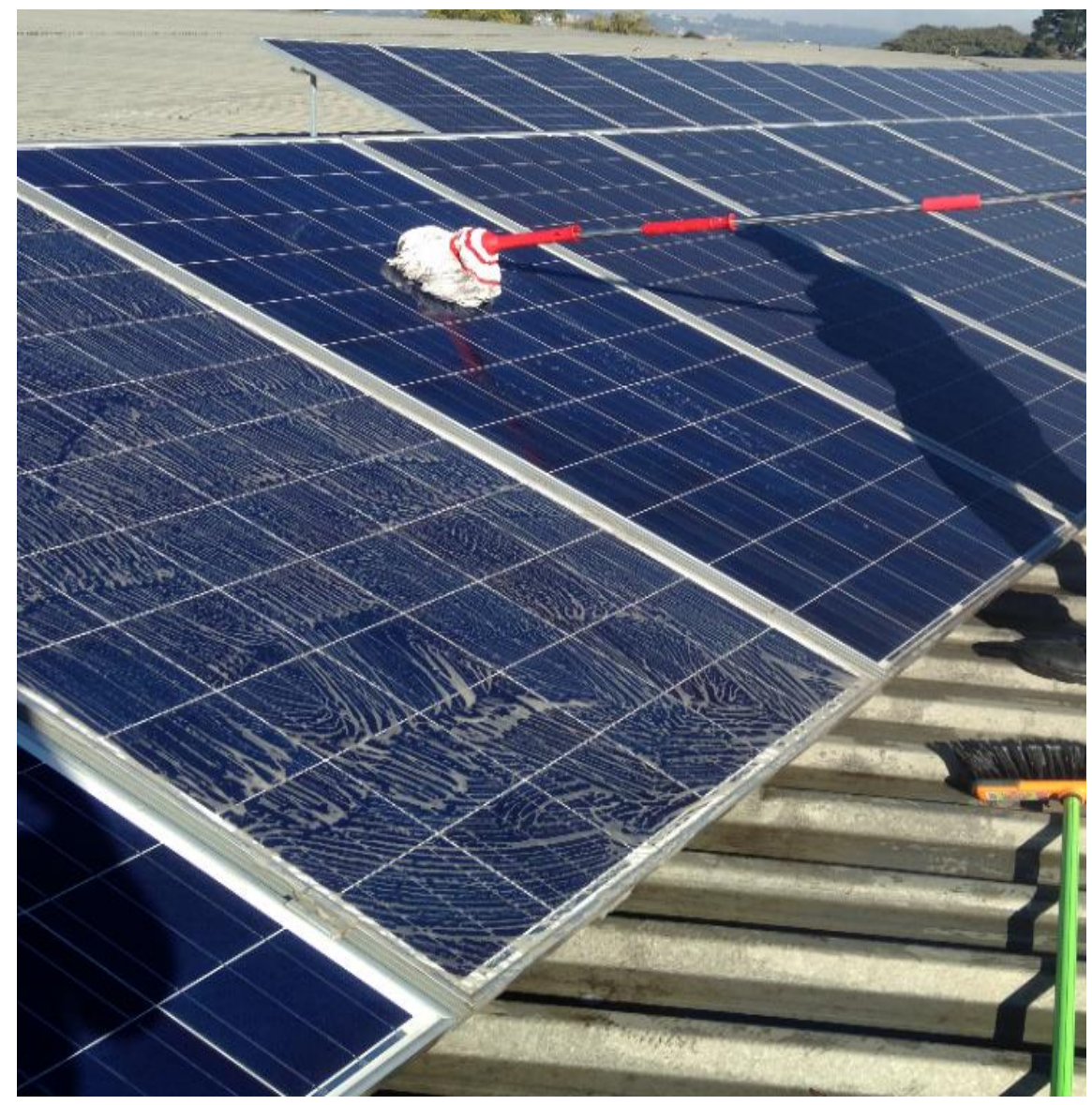

Figure 3 - Cleaning the modules in Neoville

In addition to the irradiance data analysis, the mass memory of the inverters of the two systems were accessed and the electric power data acquisition was performed in order to be analyzed and compared. The data is available with values every 15 minutes

\section{RESULT AND DISCUSSION}

Daily irradiance curves from May to August 2017 were analyzed and two days, 06/17/17 and 07/13/17, were chosen.

For both $\mathrm{GO}$ and Neoville, the same methodology was used. The difference is that because the pyranometer and GO are located in the same facility, just a few meters distant from each other, the irradiance data used came from this equipment. For the Neoville, the irradiance data considered in this analysis came from INMET, because the UTFPR's pyranometer and Neoville are quite distant from each other. The INMET data were also used to compare the accuracy of UTFPR's equipment data.

A comparative graph of the irradiance data can be observed in Figure $4(A)$, and the similarity in the irradiance behavior can be noticed, and Figure 4 (B) shows the power values throughout the day. 
Table 1 shows a summary of the values obtained, and it is possible to observe that the data are quite similar, both the peak values and the mean values.

Table 1 - Parameters of the studied days

\begin{tabular}{|c|c|c|}
\hline Parameters & Day 17/06/2017 & Day 13/07/2017 \\
\hline Peak value & $683.7\left[\mathrm{~W} / \mathrm{m}^{2}\right]$ & $678.6\left[\mathrm{~W} / \mathrm{m}^{2}\right]$ \\
\hline Peak Value Time & 12:08:00 & 12:06:00 \\
\hline Total Irradiation & $4,218.35\left[\mathrm{Wh} / \mathrm{m}^{2}\right]$ & $4,303.93\left[\mathrm{Wh} / \mathrm{m}^{2}\right]$ \\
\hline Energy Produced & $7.99[\mathrm{kWh}]$ & $8.49[\mathrm{kWh}]$ \\
\hline Irradiation's Difference & \multirow{2}{*}{\multicolumn{2}{|c|}{$\begin{array}{l}2.03 \% \\
6.26 \%\end{array}$}} \\
\hline Production Increasing & & \\
\hline Average temperature & $16.6^{\circ} \mathrm{C}$ & $15^{\circ} \mathrm{C}$ \\
\hline
\end{tabular}

Data acquired to study the conditions in the Green Office

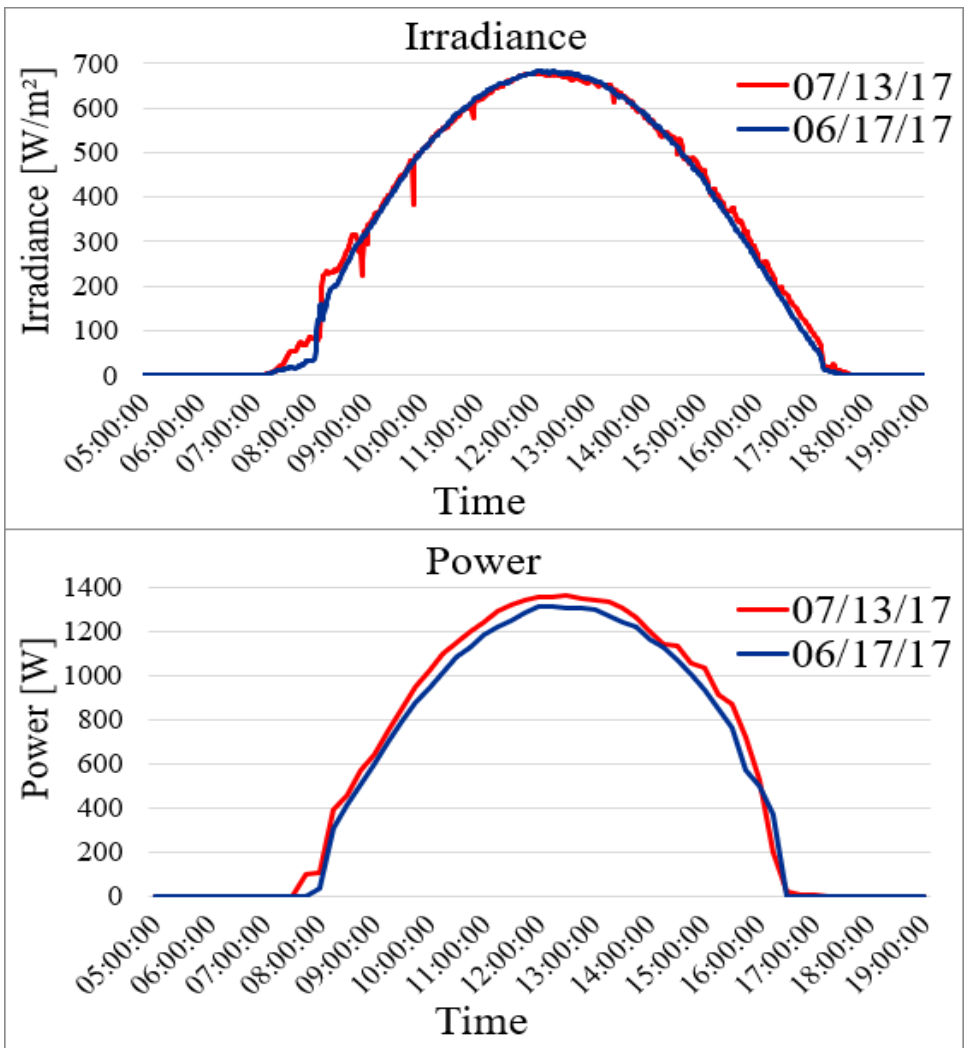

Figure 4 - Comparison of daily irradiance in $\mathrm{W} / \mathrm{m}^{2}(\mathrm{~A})$; Comparison of power in $\mathrm{W}$ in the Green Office (B)

Analyzing Table 1 , it is observed that $07 / 13 / 17$ presents a slightly higher total irradiance value when compared to June 06/17/17, and it is observed in Figure 4 (B) a higher energy value produced. For most of the day, the irradiance curves are superimposed, except in some specific moments, when the power curve observed on 07/13/17 is superior. At the end of the day, a generation higher than $6.26 \%$ was calculated compared to the day prior to cleaning.

For the Neoville system, as well as in the GO, a comparative graph of the irradiance data was drawn, and it can be observed in Figure 5 (A) that there is a similarity in the behavior of the irradiance, and in Figure 5 (B) power values are displayed during the day.

In Table 2 a summary of the values obtained are presented, in which it can be observed that the data are quite similar, both the peak values and the mean values. The average temperature for days is also similar. 
Table 2 - Parameters of the studied days

\begin{tabular}{|c|c|c|}
\hline Parameters & Day 17/06/2017 & Day $13 / 07 / 2017$ \\
\hline Peak value & $671\left[\mathrm{~W} / \mathrm{m}^{2}\right]$ & $655.55\left[\mathrm{~W} / \mathrm{m}^{2}\right]$ \\
\hline Peak Value Time & 12:00:00 & 12:00:00 \\
\hline Total Irradiation & $4,205.20\left[\mathrm{Wh} / \mathrm{m}^{2}\right]$ & $4,182.92\left[\mathrm{Wh} / \mathrm{m}^{2}\right]$ \\
\hline Energy Produced & $49.40[\mathrm{kWh}]$ & $49.80[\mathrm{kWh}]$ \\
\hline Irradiation's Difference & \multirow{2}{*}{\multicolumn{2}{|c|}{$\begin{array}{c}-0.53 \% \\
0.81 \%\end{array}$}} \\
\hline Production Increasing & & \\
\hline Average temperature & $16.6^{\circ} \mathrm{C}$ & $15^{\circ} \mathrm{C}$ \\
\hline
\end{tabular}

Data acquired to study the conditions in Neoville

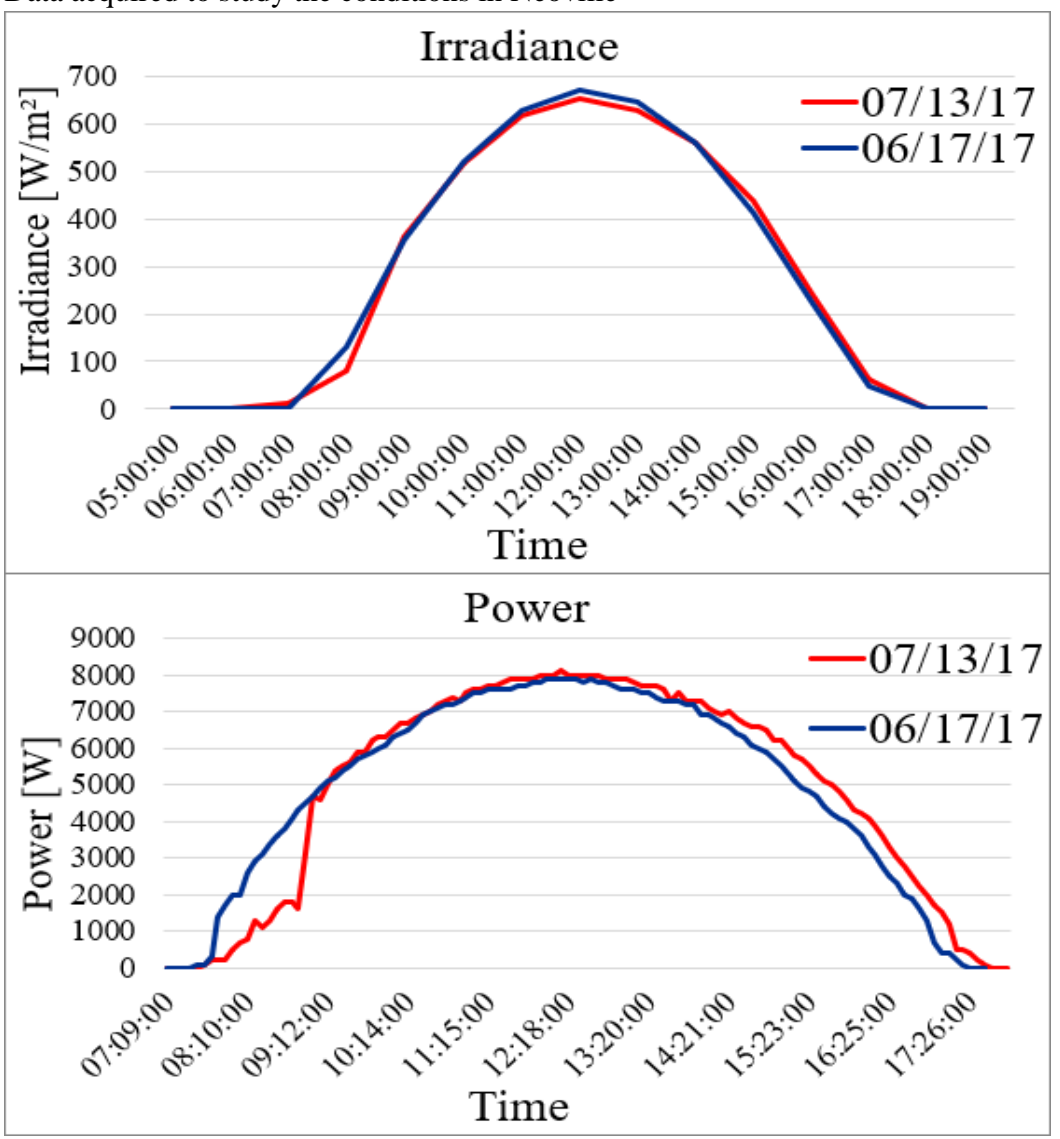

Figure 5 - Comparison of daily irradiance in $\mathrm{W} / \mathrm{m}^{2}(\mathrm{~A})$; Comparison of power in $\mathrm{W}$ at Neoville Headquarters (B)

Analyzing Table 2 , it is observed that $06 / 17 / 17$ shows a slightly higher total irradiance value when compared to 07/13/17, and it is observed in Figure 5 (B) a higher energy value produced for $07 / 13 / 17$. For most the whole day, the irradiance curves are superimposed and the power curve observed on 07/13/17 is higher, except at the beginning of the day. At the end of this day, a value of $0.81 \%$ higher generation was calculated, although the irradiation on this day was $0.53 \%$ lower than the day before to the cleaning.

\section{CONCLUSION}

Analyzing Table 1 and Table 2 and comparing the irradiation data, it can be observed that for the date 06/17/17 the values collected from the pyranometer and the INMET show similarity, variation of $0.31 \%$, and on day $07 / 13 / 17$, there is a difference in irradiation values of approximately $2.89 \%$. These differences occur because the UTFPR's pyranometer and the INMET's collection system are in different and distant 
locations, and because both have different data acquisition frequencies, where the UTFPR's equipment displays collected data every minute and in the INMET's portal the collected data are available every hour. Comparing the maximum values of irradiance, both data collection systems have very similar values.

The values of energy produced and power were obtained by accessing the mass memory of the inverters, in which we were able to construct the presented graphs.

Comparing the electric power production data in the GO, although there was an increase of $2.03 \%$ in the irradiation, there was a $6.26 \%$ increase in the energy produced. The days had a quite very equivalent temperature behavior, with a final average temperature around $16^{\circ} \mathrm{C}$. It can be stated that this increase was significantly influenced by the cleaning of the modules.

Neoville's electricity generation data also showed the expected result, resulting in an increase in production, but with a smaller proportion when compared to the GO's. Observing the power curve, in red (day after cleaning) of Figure 5(B), we realize that it shows at the beginning of the day values above the power curve in blue (day before cleaning). Thus, even though the graph shown in Figure 5 (A), the irradiance showed similar levels between themselves. The power decreasing at the beginning of the day can be explained by variations of cloudiness in the different locations of the city of Curitiba, since Neoville and INMET are far from each other.

Although the proposed analysis was limited to the data collection period of irradiation and electric energy production, there was a significant increase in the productivity of these systems. Therefore, the study carried out proves that factors as dirt must be known and not ignored for optimization of energy production.

Finally, it is emphasized that in this study a daily analysis of irradiance and energy produced from the PV system of the buildings under study was performed. However, in future, studies can be made by expanding to a monthly study, aiming at a more accurate acquisition of the generation data. Therefore, the present article met the objective established in this study, demonstrating from collected data in operating PV systems, the effect of dirt on the performance of the two systems.

\section{REFERENCES}

1- Renewables 2017 Global Status Report - [cited 2017 Aug 10]. Available from: http://www.ren21.net/wp-content/uploads/2017/06/178399_GSR_2017_Full_Report_0621_Opt.pdf2017

2- National Electrical Energy Agency: Generation Database - [cited 2017 Aug 19]. Available from: http://www2.aneel.gov.br/aplicacoes/capacidadebrasil/capacidadebrasil.cfm

3- National Electrical Energy Agency: Distributed Micro and Minigerators Records made effective at ANEEL - [cited 2017 Aug 19]. Available from: http://www2.aneel.gov.br/scg/gd/GD_Fonte.asp

4- Urbanetz Jr J, Tiepolo GM, Casagrande Jr EF, Tonin FS, Mariano JD. [Photovoltaic Distributed Generation: The Case of UTFPR Photovoltaic Systems in Curitiba]. Congresso Brasileiro de Planejamento Energético. 2016 Sep 26-28;12(5). Portuguese.

5- Almeida LT. [Implantation of a Thermoelectric Pyranometer at the UTFPR for Analysis of Solar Energy Potential in this Locality] [Final course assignment] 2015; 94(38). Portuguese.

6- Pinho JT, Galdino MA. Engineering manual for photovoltaic systems. Rio de Janeiro: Creserb Cepel; 2014. p. 66-101

7- Araújo AJN, Bueno TBA, Rank NI. [Analysis of the Loss Factors in the Grid Tie Photovoltaic Systems in Curitiba] [Final course assignment] 2016; 85(34). Portuguese.

8- National Institute of Meteorology [cited 2017 Aug 14]. Available from: http://www.inmet.gov.br 